\title{
Peer-review variations
}

\section{In our trial of a double-blind procedure for peer review, authors' awareness of their peer-review choices in the early stages of writing a paper is key for their decision to opt in or out.}

Half a year ago, Nature Geoscience and Nature Climate Change started to offer authors the option to remain anonymous to referees ('double-blind review'). We intended to remove at least some of the bias associated with affiliation, personal reputation, gender or nationality from the peer review process (Nature Geosci. 6, 413; 2013). Since then, we have gathered numbers on submission and participation, as well as authors' opinions, to get a better idea of what influences our authors' choice to opt in or out. Intriguingly, although three quarters of respondents in our 2012 reader survey supported the principle of double-blind peer review (Nature Geosci. 5, 585; 2012), participation so far has amounted to only about $15 \%$ of authors overall.

The discrepancy made us curious. To understand the numbers better, we have been (and still are) inviting the corresponding authors of all submissions to Nature Geoscience and Nature Climate Change to complete a short survey on peer review, with a specific focus on our trial of the double-blind procedure. It turns out that a significant stumbling block to participation in the trial is the necessity for authors to ensure the paper does not reveal their identity. Very few authors knew before they started writing their papers (or early on in the process) that they were going to have the choice to go double-blind. Understandably, those who did not know about this option were reluctant to delay their submission once they had finalized their manuscript and were asked to choose between the double-blind and traditional peer-review options.

Time, together with further efforts from us to make the trial better known, should help raise awareness with those in the critical early phases of writing a paper. We take heart from the fact that more than half of those who chose the traditional peer-review process this time said they were quite likely or very likely to go for the double-blind process next time they submit to Nature Geoscience or Nature Climate Change - now they know that they have the option.

Other more systematic criticisms of the trial were also raised in the survey. To us, the most significant objection was that a double-blind peer review system works best when it is mandatory, rather than optional as in our trial. As one survey participant put it: "Those likely to benefit from their institutional affiliations and reputations will choose single-blind and still benefit from that discrimination." We would not take the step of making double-blind review mandatory without strong demand from the community. However, we feel that this objection will become less important once a higher proportion of manuscripts take part in the trial.

About a quarter of the approximately 50 authors who filled in our survey before the cut-off date for this Editorial had chosen the double-blind peer review option - a higher, but not much higher proportion than the $15 \%$ of authors who participated in the trial overall. As such, despite some skew towards supporters of author anonymity in the survey, we are encouraged by the fact that almost all respondents agreed that the trial should continue.

From the responses we received, we gather that what is most needed is a higher awareness of the option earlier on in the writing process. Along this line, we encourage all our readers to discuss the trial with their colleagues.

\section{Arctic loss}

\section{The deaths of 11 rescue workers that set out to help a research boat in stormy Arctic waters highlights the perils of collecting data at sea.}

\section{The Arctic has been one of the}

fastest-warming regions on the globe for the past few decades, as evidenced by the recent dramatic decline in summer sea ice cover. The consequences of this rapid warming - for instance, for the vast quantities of carbon locked away in the frozen soils and icy submarine sediments that permeate the region - is a key climate concern. Data from the Arctic, like those presented on page 64 of this issue, can therefore be of immense value to the climate science community. However, making measurements in such an inhospitable environment, particularly in the icy and increasingly storm-prone waters of the Arctic Ocean, is risky. In the case of the research presented in this issue, the rescue boat that set out to assist the researchers when they hit stormy waters sank, taking 11 of the crew with it.

On 24 August 2010, the researchers headed out to a spot in the southern Laptev Sea, to the east of the Lena River delta, to verify observations from the previous summer that storms can flush methane out of the sea water. But when a storm hit on 26 August, their ship got into difficulty and they sounded the alarm. A 14-strong rescue team set out to help, but their tug boat capsized en route. A nearby tanker managed to save three of the rescuers from the icy-cold waters. Tragically, the remaining 11 rescuers died. The researchers survived unscathed.

The data taken by the surviving research team, collected over a 10-year period and presented in this issue, show that submarine sediments on the Arctic shelf are releasing significant quantities of the potent greenhouse gas methane to the overlying ocean, and that storms and bubbles mediate the flux of much of this methane to the overlying atmosphere.

The death toll associated with this research expedition is particularly high. However, Earth science fieldwork often comes with some risk attached. For instance, tree snakes and saltwater crocodiles prey on the minds of researchers in the hot humid mangroves of the tropics (Nature Geosci. 4,$344 ; 2011$ ), and the threat of piracy looms large for researchers in the South China Sea (Nature Geosci. 1, 875; 2008). Such risks make it all the more important that the hard-won data from these projects are analysed, shared and reanalysed to their full potential. 